\title{
Reducing Racial Disparity in Colorectal Cancer Burden
}

\author{
Adeyinka O. Laiyemo
}

Published online: 24 July 2014

(c) Springer Science+Business Media New York 2014

Blacks suffer the greatest burden from colorectal cancer (CRC) of all race ethnicities in the USA [1]. The mortality from CRC per 100,000 population is 28.7 for black men, 19.0 for black women, 19.2 for white men, 13.6 for white women, 13.1 for Asian men, 9.7 for Asian women, 16.1 for Hispanic men, and 10.2 for Hispanic women [1]. Factors contributing to this disparity include poorer access to preventive services such as CRC screening, lack of adequate knowledge of a family history of CRC (the single most important factor that guides screening recommendations), sub-optimal utilization of healthcare resources when available, and possible biological differences, particularly with proximal location of malignancy as a likely contributor to late-stage presentation [2]. After cancer has been diagnosed, other factors that contribute to poorer outcome among blacks include lower surgical resection rates (the intervention that offers the best chance for cure), lower utilization of chemotherapy, and poorer social support.

The current response to the observed racial disparities has focused on recommendations to screen blacks earlier than 50 years of age [3]. More frequent screening than is recommended in the general guidelines has also been reported for blacks with negative screening colonoscopy [4]. Although well intentioned, these interventions have not been proven to be effective. In this issue of the Digestive Diseases and Sciences, Kwah et al. [5] compared the risk of metachronous advanced colorectal neoplasia (ACN) for a median duration of 4.3 years following colorectal adenoma removal among comparable numbers of white and

A. O. Laiyemo $(\square)$

Division of Gastroenterology, Department of Medicine, Howard University College of Medicine, 2041 Georgia Avenue, NW, Washington, DC 20060, USA

e-mail: adeyinka.laiyemo@Howard.edu black patients. Although the overall recurrence of ACN was similar between blacks and whites (11.3 vs. $9.8 \%$, OR 1.18 ; $95 \%$ CI $0.65-2.26$ ), blacks were more likely to have ACN within 1-3 years of the index colonoscopy (15.7 vs. $7.7 \%$, OR 2.20; $95 \%$ CI 0.63-7.94). The doubling of the odds of early recurrence among blacks, albeit not statistically significant, raises a possibility of missed lesions at baseline. Although these difficult-to-obtain data are unknown from the study by Kwah et al. [5], it is noteworthy that the participants in the Polyp Prevention Trial underwent clearing colonoscopies 1 year after the initial colonoscopy to remove lesions that may have been missed at baseline examinations [6]. In that trial, there was no racial difference in the findings of missed adenoma ( 33.8 vs. $34.9 \%$, RR $0.97 ; 95 \%$ CI $0.77-1.22$ ) or missed advanced adenoma (5.6 vs. $6.0 \%$, RR $0.97 ; 95 \% \mathrm{CI}$ 0.49-1.91.

Although the study by Kwah et al. [5] is limited by its retrospective design and small sample size, it provides additional evidence that recurrence of neoplasia may not be appreciably different between blacks and whites. So far, all studies [5-8] that have evaluated metachronous colorectal neoplasia among blacks and whites have not supported substantial racial differences in the risk of recurrence of precancerous lesions (Table 1). Thus, more frequent surveillance colonoscopies for blacks beyond the recommended guideline are not warranted, and excessive postpolypectomy surveillance is probably not going to be an effective strategy to reduce CRC disparity.

The most effective interventions will more likely address the aforementioned social, cultural, and access disparities rather than any perceived biological differences among the screened populations. In the comprehensive Delaware "Village Approach" which involved governmental sponsorship of a campaign which aggressively 


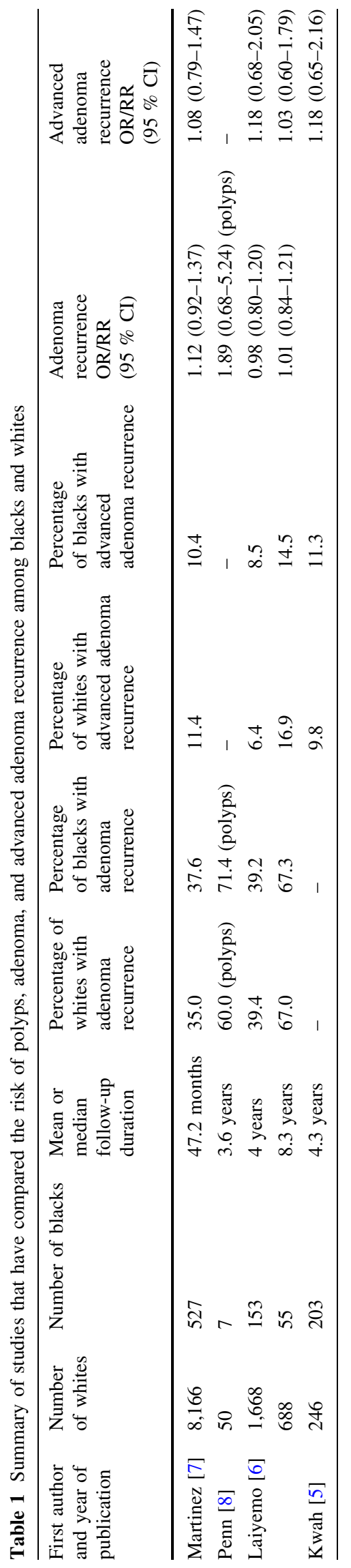

promoted CRC screening, offered healthcare access to the uninsured, utilized extensive patient navigation services, and provided treatments for patients diagnosed with cancer [9], the CRC burden among blacks was reduced. Although, the comprehensive approach is capital intensive, it is likely a sound and worthwhile investment.

Given their expense, if just one intervention is to be promoted, the greatest cost-effectiveness might accrue from the initial screening. The first screening provides the maximum opportunity for risk reduction in CRC with once-in-a-lifetime screening with flexible sigmoidoscopy reported to reduce $\mathrm{CRC}$ mortality in a randomized trial [10]. Therefore, it is more important to focus on improving the initial screening rates among blacks. It is anticipated that the Affordable Care Act should provide widespread coverage for preventive services and thereby provide increased access to CRC screening for all eligible citizens. Improved access in and of itself does not guarantee greater utilization of healthcare resources due to numerous challenges related to low health literacy, distrust of the healthcare system, and perceived discrimination. Another approach is identifying and targeting resources to black families at an increased risk for CRC, such as those with Lynch syndrome. Similarly, there is a need to encourage and facilitate timely screening of average-risk blacks and ensure prompt follow-up of abnormal screening results. Our focus should be to improve screening among blacks who have not yet been screened as the major step in reducing CRC disparity by race.

Conflict of interest None.

\section{References}

1. Siegel R, Ma J, Zou Z, Jemal A. Cancer statistics, 2014. CA Cancer J Clin. . 2014;64:9-29.

2. Tammana VS, Laiyemo AO. Colorectal cancer disparities: issues, controversies and solutions. World J Gastroenterol. 2014;20: 869-876.

3. Rex DK, Johnson DA, Anderson JC, Schoenfeld PS, Burke CA, Inadomi JM. American College of Gastroenterology. American College of Gastroenterology guidelines for colorectal cancer screening 2009 [corrected]. Am J Gastroenterol.. 2009;104: $739-750$.

4. Goodwin JS, Singh A, Reddy N, Riall TS, Kuo YF. Overuse of screening colonoscopy in the Medicare population. Arch Intern Med.. 2011;171:1335-1343.

5. Kwah J, Schroy PC, Jacobson BC, Calderwood AH (2014) Whites and blacks have similar risk of metachronous advanced colorectal neoplasia. Dig Dis Sci. (Epub ahead of print). doi: 10. 1007/s10620-014-3132-4.

6. Laiyemo AO, Doubeni C, Brim H, et al. Short- and long-term risk of colorectal adenoma recurrence among whites and blacks. Gastrointest Endosc.. 2013;77:447-454.

7. Martínez ME, Baron JA, Lieberman DA, et al. A pooled analysis of advanced colorectal neoplasia diagnoses after colonoscopic polypectomy. Gastroenterology.. 2009;136:832-841. 
8. Penn E, Garrow D, Romagnuolo J. Influence of race and sex on prevalence and recurrence of colon polyps. Arch Intern Med.. 2010;170:1127-1132.

9. Grubbs SS, Polite BN, Carney J Jr, et al. Eliminating racial disparities in colorectal cancer in the real world: it took a village. $J$ Clin Oncol.. 2013;31:1928-1930.
10. Atkin WS, Edwards R, Kralj-Hans I, et al. UK Flexible Sigmoidoscopy Trial Investigators. Once-only flexible sigmoidoscopy screening in prevention of colorectal cancer: a multicentre randomised controlled trial. Lancet.. 2010;375:1624-1633. 